\title{
On the Theory of Multiple Feature-checking: Arabic Verbs of Speech and Communication
}

\author{
Sabri S. Alshboul \\ Department of English Language and Literature, Hashemite University, Zarqa, Jordan \\ Maisoun I. Abu-Joudeh \\ Department of English Language and Literature, Hashemite University, Zarqa, Jordan \\ Nazmi T. Al-Shalabi \\ Department of English Language and Literature, Hashemite University, Zarqa, Jordan
}

\begin{abstract}
This study examines case checking in constructions controlled by verbs traditionally classified as verbs of speech and communication. These are constructions in which accusative case is licensed on more than one element. It is shown that these constructions can be offered a consistent account by the theory of multiple feature- checking. This account allows case to be multiply checked in a single configuration framework.
\end{abstract}

Index Terms - feature-checking, case, accusative

\section{INTRODUCTION}

This study presents an account of case checking in constructions controlled by a group of verbs called ?araa and its sisters by Arabic traditional grammars. These verbs take two internal arguments, the first is a nominal complement and the second an embedded clause in which both the subject and the predicate are marked as accusative. They are hada $\theta \mathrm{a}$, xabara or axbara, naba?a or anba?a, ?aSlama "to tell or inform", and 7araa "to show". The following are examples of these constructions in Modern Standard Arabic:

(1) Taflama Bakr-un Zaid-an Samr-an qadim-an

informed.3ms Bakr-nom Zaid-acc Amr-acc coming-acc

"Bakr informed Zaid that Amr is coming."

(Wright, 1976, p. 53)

(2) anba?atu Sabdullabha Zaid-an musaafir-an

informed.1s Sabdullabh-acc Zaid-acc leaving-acc

"I informed Sabdullabh that Zaid was out of the country."

(3) xabartu Zaid-an Samr-an yaa?ib-an

told.1s Zaid-acc Samr-acc absent-acc

"I told Zaid that was not present."

(4) hadattu Zaid-an Bakr-an muqiim-an told.1s Zaid-acc Bakr-acc staying-acc

"I told Zaid that Bakr was staying."

(Ibn Aqiil, 1990, p.382, 383)

(5) axabartu al-mariiD-a ar-raaha-ta laazima-tan told.1s the-patient-acc the-rest-acc necessary-acc

"I told the patient that rest was necessary."

(Hassan, 1973, p.61)

As we see in the above examples, the first NP to the right of the verb as well as the subject and predicate of the embedded small clause are marked with accusative case.

\section{CASE CHECKING}

Assuming that accusative case is generally assigned by transitive verbs, it is important to provide an analysis that explains how two NPs in one structure bear the same case features. In other words, a configuration in which two NPs 
get to check the same case features needs to be proposed. As a first step towards developing such an analysis, I assume that the D-structure of a construction like (1) is represented as in (6):

(6)

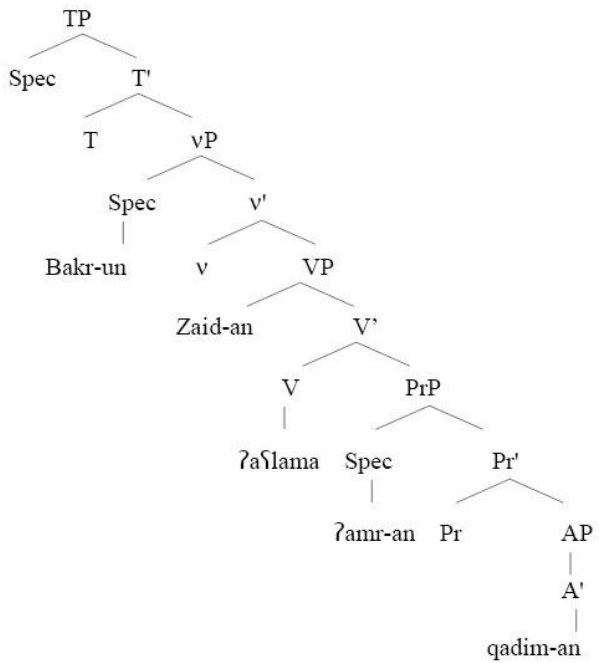

The assumption is that the base-generated DP (objective complement) Zaid-an moves to a Spec of vP. This movement is followed by the subject of the embedded small clause $\zeta$ amr-an raising to an inner Spec of $v \mathrm{P}$. Once they reach their ultimate positions, the two DPs enter into a checking relation with the verb of the matrix clause which as we assume allows for a multiple checking of its accusative case- feature. We also assume that the verb first moves up to merge with the lightv. The motivation for the movement of the verb is to provide the configuration under which case checking will take place. The predicate of the equative sentence checks its accusative case under agreement with the subject. This is mediated via the trace of the subject. After case checking is achieved, the verb raises overtly to $\mathrm{T}$ to check its $[+\mathrm{V}]$ features. The subject is not motivated to move to the Spec of TP because the nominal features of T are not strong in Arabic. Thereby (7) is derived from (6):

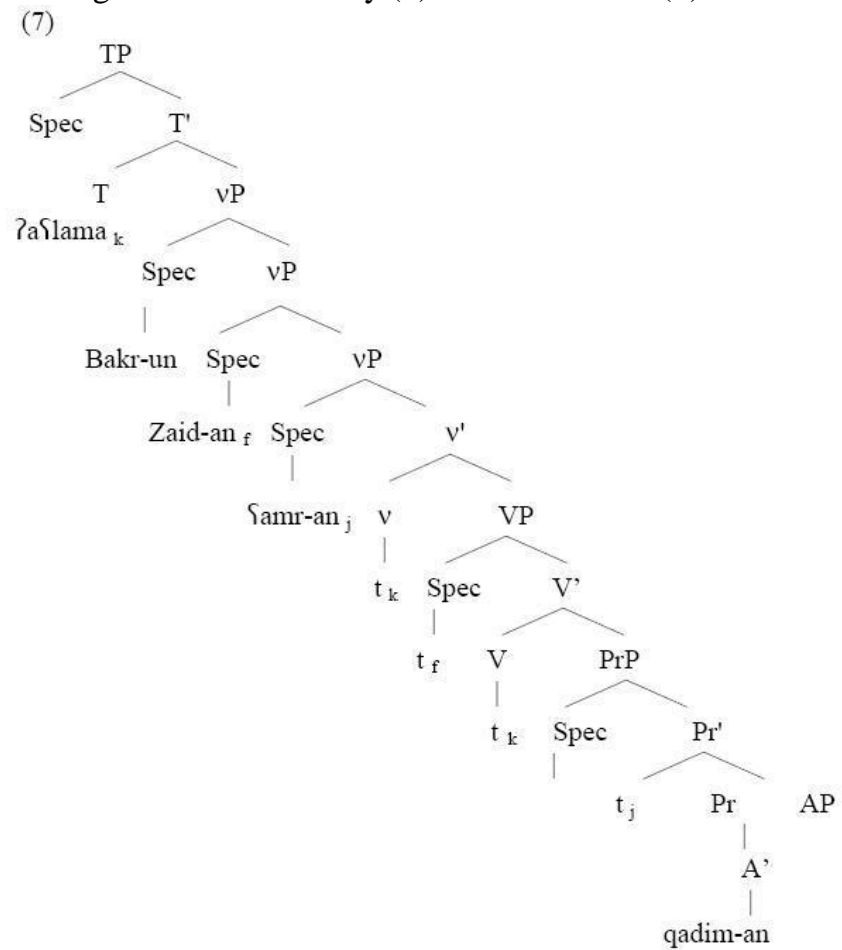

Adopting Bowers' (1993) theory of predication, it is assumed that embedded equative sentences in Arabic may have a standard X-bar representation in which the subject occupies the specifier position of PredP and the predicate occupies the complement position of Pred. This provides the configuration in which the predicate gets to check its accusative case feature by agreeing with the subject (cf.Abujoudeh, 2013). The assumption that the predicate of the equative sentence checks its accusative case-feature via agreement with the subject is empirically supported. There is empirical evidence that when the subject of the equative sentence moves to a peripheral position and its case shifts from accusative to nominative, the same is expected to occur to the predicate. This predication is borne out in the following examples: 
(8) ZaSlamatu Zaid-an la-Samr-un qaiim-un

told-1s Zaid-an truly-\{amr-nom standing-nom

"I told Zaid that Yamr was standing up."

(9) Samr-un ZaSlamatu Zaid-an qaiim-un

Samr-nom told-1s Zaid-an standing-nom

"I told Yamr that Zaid was standing up."

(Ibn Aqiil, 1991, p.387)

When the negation particle $L a$ - introduces the predicative phrase, both the subject and the predicate get the nominative case. Notice that in (9) the predicate still agrees with the subject even when it moves to a peripheral position. This suggests that the predicate checks its case under agreement with the subject.

Another refinement could be made to the analysis proposed above for how case in these multiple-accusative constructions in Arabic is checked. The case feature of the verb in Arabic, being [+multiple] can enter into an agree relation with all the elements in one single operation. This is partly based on Chomsky's (2001) theory of Agree which eliminates the feature- movement part of ATTRACT developed in Chomsky (1995) and proposes instead "a relation Agree holding between $\alpha$ and $\beta$, where $\alpha$ has interpretable inflectional features and $\beta$ has uninterpretable ones, which delete under Agree" (2001, p.3). The assumption is that the $\Phi$-features of the probe (T orv) are interpretable and agree with the uninterpretable $\Phi$-features of $\mathrm{N}$. Case is not matched itself but deletes under agreement.

Following Hiraiwa (2001), we further assume that case checking in multiple-accusative constructions does not require the verb to enter into multiple applications of the same operation. Rather it is proposed that the verb in these constructions undergoes one single simultaneous syntactic operation. Hiraiwa (2001, p.70) poses that at the point of the derivation where the probe is introduced by merge, it starts to probe for a closest matching goal within its c-command domain and matches with the closer goal $\beta$. Since the probe feature is [+multiple], the probe continues to look for a next closest goal within the active phase, which results in matching with $\gamma$. It is at this point, states Hiraiwa (2001) that "Agree applies to all the matching goals derivationally simultaneously, establishing AGREE $(\alpha, \beta, \gamma)$. Thus under MULTIPLE AGREE, a superficial 'covert multiple feature-checking' is not multiple instances of the syntactic operation AGREE; rather it is reduced to a single syntactic operation." So we assume that the verb in multiple-accusative constructions enters into one single feature-checking operation by agreeing with the matching goals via long-distance. This operation comes problem-free since the goals are equally distant from the verb and no intervening elements come between them. That is to say, the cost of matching with one goal and holding till the probe finds its other goal is not in any way problematic for the derivation.

To conclude, the above assumptions are consistent with economy conditions since they eliminate movement unless absolutely necessary. Hiraiwa's assumptions are also consistent with the fact that the verb in Arabic has a [+multiple] case feature that results in overt morphological case on the two objects in double-object constructions. However, they differ in the sense that case checking is not a series of multiple applications of the same operation but rather one single syntactic operation in which the probe agrees with all the matching goals simultaneously.

Hiraiwa (2001, p.73) provides support for his theory of MULTIPLE AGREE from an interaction of Exceptional Case Marking (ECM) and Possessor-Raising Construction in Japanese.

(10) a. John-ga [CP [TP Mary-ga me-ga waru-i] to ] omikondei-ta. John-NOM Mary-NOM eyes-NOM bad-PRES C believe-PST "John thinks that Mary has a bad eyesight."

b. John-ga [CP [TP Mary-o me-ga waru-i] to] omikondei-ta. John-NOM Mary-ACC eyes-NOM bad-PRES C believe-PST

c. * John-ga [CP [TP Mary-ga me-o waru-i] to ] omikondei-ta.

John-NOM Mary-NOM eyes-ACC bad-PRES C believe-PST

The contrast in grammaticality between (10b) and (10c) clearly shows that a probe cannot have an Agree relation with a matching goal beyond another inactive matching goal. ${ }^{1}$ In $(10 \mathrm{~b})$ the closer goal in the outer TP specifier is ECMed, whereas in (10c) it is the lower goal in the inner specifier position of TP that is ECMed. Therefore, there is no way for $v$ as a probe to ECM a lower goal beyond an intervening inactive goal. The intervening goal is inactive due to a prior Agree with the embedded $\mathrm{T}$ at the point of the derivation where the probe $v$ is merged. The theory of MULTIPLE AGREE and the DIC as developed by Hiraiwa (2001, p.74) makes a crucial predication: "if a probe for multiple goals is derivationally unique, then multiple ECM should be grammatical in the ECM construction in Japanese". This prediction is to be validated by examples like the following (Hiraiwa 2001, p.75):

(11) \#John-ga [CP [TP Mary-o me-o waru-i] to ] omikondei-ta. John-NOM Mary-ACC eyes-ACC bad-PRES C believe-PST "John believed Mary's eye to be bad."

\footnotetext{
${ }^{1}$ The Defective Intervention Constraint (cf Chomsky 2000:123) which states that no AGREE relation is established between a probe and a matching goal when an inactive goal intervenes.
} 
However, due to the Double-O Constraint, which does not allow an accusative marker to occur more than once within a sentence, this sentence is ruled out as ungrammatical. One way to overcome the problem is to cleft the sentence. Thus the cleft version of the sentence is grammatical with multiple ECM:

(12) John-ga [CP [TP $t_{i}$ me-o wariu-i] to] omoikondei-ta no] wa Mary- $\mathrm{O}_{\mathrm{i}}$ da. John-NOM eyes-ACC bad-PRES C believe-PST-AND C-TOP Mary-ACC CPL

"It is Mary that John believed her eye to be bad."

It follows that the matrix $v$ is properly allowed to check the accusative case on the lowest goal as well as on the closer accusative goal. The same result is gained when combining the "multiple cleft" test with multiple ECM as the following examples show:

(13) \#John-ga Mary-o taido-o insei-ni (-taisite) tsumeta-ku/tumeta-I to] omot-ta John-NOM Mary-ACC attitude-ACC grad.students-DAT cold-INF/cold-PRES C think-PST "John felt that Mary is cold to graduate students."

(14) [John-ga $\left[\mathrm{t}_{i}\right.$ taido-o $\mathrm{t}_{i}$ tsumeta-ku/tumetai to] omot-ta no]-wa Mary- $\mathrm{o}_{i}$ insei-ni (-taisite ${ }_{i}$ )da. John-NOM attitude-ACC cold-INF/cold-PRES C think-PST C-TOP Mary-ACC grad.students-DAT CPL "(Lit.) It is Mary, to grad students that John feels cold."

(Hiraiwa 2001, p.75):

As the above examples show, multiple accusative DPs are in an agree relation with the matrix verb. We conclude that the theory of MULTIPLE AGREE as proposed by Hiraiwa (2001) accounts for covert multiple feature-checking phenomenon in languages like Japanese and Arabic. It provides a convincing explanation for the multiple occurrences of accusative case on more one element in ECM constructions.

\section{Cross-Linguistic Applications of Multiple CASE Checking}

The constructions investigated in this section provide an entirely new line of support for the analysis proposed in the previous section. It will be shown that the multiple feature-checking approach accounts for the appearance of the same case features on more than one element in the same construction. It will be argued that $\mathrm{T} / \mathrm{v}$ in the languages under consideration is endowed with an uninterpretable [+multiple] feature that enters into more than one checking relation. Multiple accusative constructions are not uncommon in the languages of the world. Ura (2000) conducts a crosslinguistic survey and finds out that there are many languages in which both objects of a ditransitive verb are marked in the same way as the typical transitive object. Among these languages are Korean, German, Malagasy, Ormo, Modern Standard Arabic, Modern Greek, and Yindijbarndi. The following are representative examples:

Malagasy (from Keenan, 1976, p.251)

(15) nanome azy an-dRabe aho gave it (acc) acc-Rabe I "I gave it to Rabe."

Greek (from Anagnostopoulou, 2000, p.11)

(16) Didaksa ta pedhia tin grammatiki ton Arxeon. taught- 1sg the children (Acc) the grammar (Acc) the Ancient "I taught the children the grammar of Ancient G reek"

(17) Servira ton pelati enan kafe served-1sg the customer (Acc) a coffee (Acc) "I paid the customer a coffee"

German (from Czepluch, 1988, p.83)

(18) Sie haben den jungen das Lied gelehrt they have the boy (acc) the song (acc) taught "They have taught the boy the song."

Korean (Shibatani, 1977, p.804)

(19) Nae ka ai ril yəngə ril karichiətta. SU-NOM IO-ACC DO-ACC I child English teach-PAST-IND (icative) "I taught English to the child."

(20) Nae ka ai ril chaekil cuətta. SU-NOM IO-ACC DO-ACC I child book give-PAST-IND "I gave a book to the child."

(21) Nae ka ai ril papil məki-ət-ta. SU-NOM IO-ACC DO-ACC I child rice feed-PAST-IND

"I fed the rice to the child."

Yindijbarndi (from Dryer, 1986, p.829)

(22) Nagaarta yungku-nha ngayu murla-yi 
man-NOM give-PAST me-OBJ meat-OBJ

"A man gave me the meat."

As shown in the above examples, both objects have the same case morphology and are contiguous. Therefore, we propose that the account developed in the present study extends interestingly to these languages. We assume that the verb in these languages allows for multiple checking of its accusative case feature.

Multiple nominative constructions present good empirical evidence for multiple feature-checking. It will be demonstrated that $\mathrm{T}$ in the languages under investigation has an uninterpretable [+multiple] case feature that can enter into more than one checking relation. This assumption will account for the appearance of nominative case on more than one element. Modern Hebrew, Japanese and Modern Standard Arabic are among the languages that allow more than one nominative phrase in a single clause. It has been noted that more than one phrase can surface in Japanese bearing the nominative case marker -ga (cf. Kuno 1978, Kuroda 1978, Shibatani 1978, Miyagawa 1989, Saito 1982, Akiyama 2004). Consider the following examples:

(23) Ano oya-ga kodomo-ga atama-ga ii. that parent-NOM child-NOM head-NOM good "It is that parent whose child is smart.

(24) Boku -ga kono hon -ga yomi-t I - NOM this book- NOM read-want "I want to read this book."

(25) Tanaka ga musuko ga sinda. Tanaka-NOM son- NOM died "Tanaka's son died." (From Miyagawa ,1989,p.102,192)

(26) mary - ga kami -ga nagai (koto) Mary-NOM hair-NOM long (fact)

"Mary has long hair"

(27) yoi otya-ga nihonzin-ga kononde nomu (koto) good green-tea-NOM Japanese-NOM enjoying drink (fact)

"Good green tea, Japanese people drink [it] with pleasure."

(From Doron \& Heycock, 1999, p.70)

Doron and Heycock (1999, p.71) argue that the initial nominative phrase in these constructions is a subject followed by a sentential predicate which already contains a subject. These initial phrases (Broad Subjects as called by Doron and Heycock) have all the properties exhibited by thematic subjects (henceforth Narrow Subjects). They can, for example, freely alternate between nominative and accusative case marking when they occur in the complement clause of ECM verbs. In this respect, they act just like Narrow Subjects as shown by the following example (from Doron and Heycock, 1999, p.72)

(28) boku-ga john-o/-ga imooto-ga kirei-da to omowu

I-NOM John-ACC/NOM sister-NOM beautiful-be that think

"I think that John's sister is beautiful."

They also behave like thematic subjects in binding the reflexive zibun:

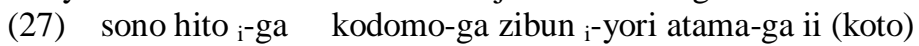
that person i-NOM child-NOM self $i$-than head-NOM good (fact)

"That person ${ }_{i}$ [is such that his/her] child is more intelligent than him ${ }_{i} /$ her $_{i}$."

The ability to bind zibun is significant for two reasons. First, it suggests that Broad Subjects are in A-positions since binding of anaphors is only possible from A-positions. Second, zibun is known as a "subject-oriented anaphor" and thus binding it implies the subjectivity of the antecedent.

Akiyama (2004, p.672) also argues for the subjecthood of the initial nominative phrases. He points out that both can control an embedded pro while a genitive DP cannot:

(28) a. [[Taro-no $\left.\mathrm{i}_{\mathrm{i}}\right]$ musuko]-ga $\mathrm{j}_{\mathrm{j}}\left[\right.$ pro $\left\{{ }_{\mathrm{i}} / \mathrm{j}\right\}$ [ryuugaku-si -tei-ru] aida-ni] sin-da.

[Taro-Gen son]-Nom study abroad-do-ASP-PRES-while-die-PAST

"Taro's son ${ }_{\mathrm{j}}$ died while he ${ }_{\mathrm{j}}$ was studying abroad."

b. [[Taro-ga $\left.\mathrm{i}_{\mathrm{i}}\right]$ musuko]-ga $\mathrm{j}_{\mathrm{j}}$ fukoo-ni-mo [[pro $\left\{\mathrm{i}_{\mathrm{i}}\right\}$ [ryuugaku-si -tei-ru] Taro-Nom unfortunately

aida-ni] sin-da.

"Unfortunately, Taro's ${ }_{\mathrm{i}}$ Son $_{\mathrm{j}}$ died while he ${ }_{\mathrm{i}} \mathrm{j}_{\mathrm{j}}$ was studying abroad."

c. Taro-ga fukoo-ni-mo [[pro $\left\{{ }_{i} / j\right\}$ ryuugaku-si -tei-ru $]$ aida-ni $]$ musuko]-ga $\sin -\mathrm{da}$

Based on the evidence so far presented, Doron and Heycock (1999) and Akiyama (2004) conclude that the initial nominative phrases in the constructions above are indeed subjects. They exhibit all the properties presumably associated with thematic subjects. However, they are different from Narrow Subjects in a number of respects. Most importantly, they are base-generated in [Spec, TP] while Narrow Subjects are base-generated within the VP, and thus their existence 
in $[$ Spec, TP] is due to movement. That is, the occurrence of these nominative phrases in multiple specifiers of TP is the result of two different operations: Move in the case of Narrow Subjects and Merge in the case of Broad Subjects (Doron and Heycock, 1999, p. 77).

A straightforward piece of evidence for base-generation comes from Modern Standard Arabic where Broad Subjects cannot trigger verbal agreement. Consider the following illustrative examples:

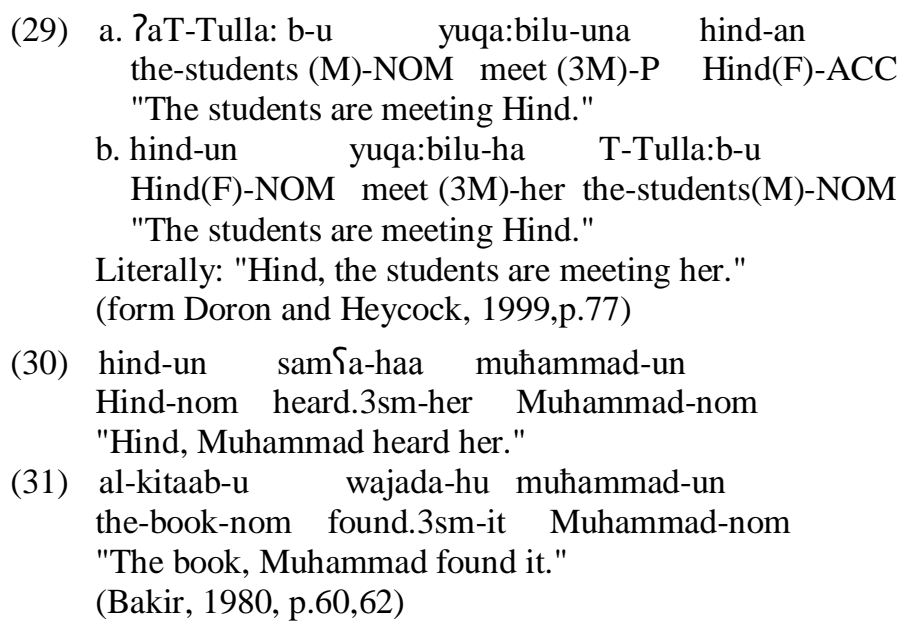

In (29), for example, the Broad Subject is the first nominative Hind-un "Hind" while the Narrow Subject is PaTTulla: $b-u$ "the students." Based on Chomsky's proposal that features cannot be checked by an element in the position in which it is merged, Doron and Heycock conclude that the Broad subject Hindun is merged at [Spec, TP] and thus cannot check agreement features there.

Now with these facts in mind, it is reasonable to assume that these NPs all enter into a checking relation with $\mathrm{T}$. That is, $\mathrm{T}$ is a probe that has an uninterpretable [+multiple] feature that can undergo several operations of checking. Once $\mathrm{T}$ is introduced, the Narrow Subject moves covertly to an inner Spec of TP, followed by the merge of the Broad Subject. It is at this point in the derivation that they enter into a checking relation with T. Therefore, a sentence like (29b) above has the D-structure in (32a) and the S-structure in (32b), with the tree (32c):

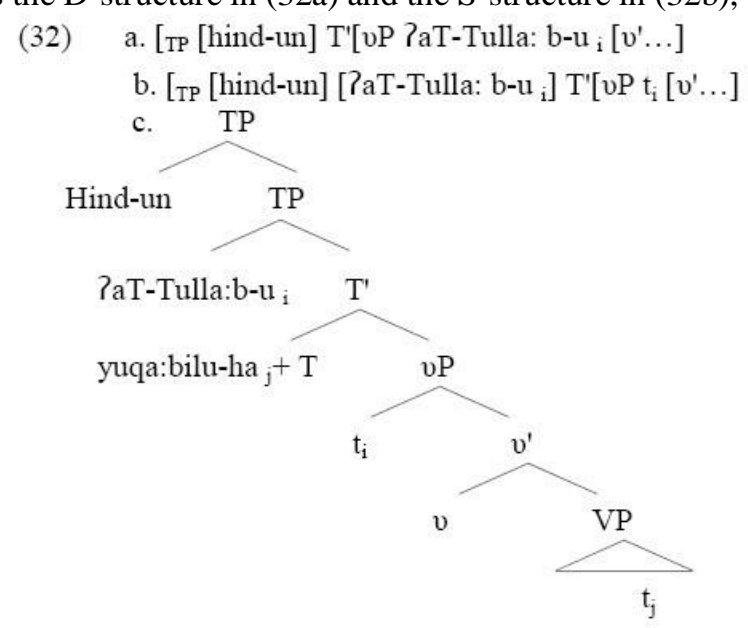

To conclude, the cross-linguistic data provided above presented empirical evidence for multiple feature-checking as proposed by Chomsky (1995) and Ura (2000). We have argued that the assumption that $v$ and T may allow for multiple feature-checking provides an insightful analysis of constructions involving multiple accusative and nominative constructions in the languages under consideration

\section{CONCLUSION}

We have presented an account of case checking in constructions governed by Arabic verbs of communication and speech. Following Ura (2000), we have argued that these verbs allow a multiple checking of their accusative case feature. Under this analysis, multiple specifiers of $\nu \mathrm{P}$ are projected to provide positions where the nominal DP and the subject of the embedded clause get to check their case features by entering each into a checking relation with the verb under a Spec-head configuration. Empirical as well as cross-linguistic evidence has been given to support the proposed account. 


\section{REFERENCES}

[1] Abujoudeh, M. (in press). Multiple feature checking in verbless sentences functioning as embedded clauses in modern standard Arabic: A minimalist account. Theory and Practice in Language Studies 2.

[2] Akiyama, M. (2004). Multiple nominative constructions in Japanese and Economy. Linguistic Inquiry 35. 4, 671-681.

[3] Anagnostopoulou, E. (2000). Two classes of double object verbs: The role of zero morphology. In: Paper presented at the $23^{\text {rd }}$ GLOW Workshop on Zero-Morphology, Bilbao, April 2000.

[4] Bakir, M. J. (1980). Aspects of clause structure in Arabic: A study of word order variation in literary Arabic. Ph.D. dissertation, Indiana University, Bloomington.

[5] Chomsky, N. (1981). Lectures on government and binding. Dordrecht: Foris.

[6] Chomsky, N. (1993). A minimalist program for linguistic theory. In K. Hale and S. Keyser (eds.), The View from Building (vol.20) .Cambridge: The MIT Press, 1-52.

[7] Chomsky, N. (1995). The minimalist program. Cambridge: MIT Press.

[8] Chomsky, N. (2000). Minimalist inquiries. In R. Martin et. al. (eds.) Step By Step: Essays on Minimalist Syntax in Honor of Howard Lasnik. Cambridge, Mass.: The MIT Press.

[9] Chomsky, N. (2001). Derivation by phase. In Kenstowicz, M. (ed.) Ken Hale: A Life in Language. Cambridge, Mass: MIT.

[10] Czepluch, H. (1988). Case patterns in German: Some implications for the theory of abstract case. McGill working papers in linguistics, special issue on contemporary German syntax, 79-122.

[11] Doron, E. and C. Heycock (1999). Filling and licensing multiple specifiers. In David Adger, Susan Pintzuk, Bernadette Plunkett, and George Tsoulas (eds.), Specifiers: Minimalist Approaches. Oxford: Oxford University Press, 69-89.

[12] Dryer, M. (1986). Primary objects, secondary objects, and antidative. Language 62,808-845.

[13] Hassan, A. (1973). Al-nahu al-waafi. Cairo: Dar Al Marrif.

[14] Hiraiwa, K. (2000). Multiple agree and the defective intervention constraint in Japanese. MIT Working Papers in Linguistics 40, 67-80.

[15] Hiraraiwa, K. (2001). Multiple agree and the defective intervention constraint in Japanese. In Ora Matsushansky et. al. (eds.), The Proceedings of the MIT-Harvard Joint Conference (HUMIT 2000) MIT Working Papers in Linguistics 40. Cambridge, MA: MITWPL, 67-80.

[16] Keenan, E. (1976). Remarkable subjects in Malagasy. In Charles N. Li (ed.), Subject and Topic. New York: Academic Press, 249-301.

[17] Keenan, E. (1992). Morphology is structure: A Malagasy test case. In Paul, I., Phillips, V., and Travis, L. (eds), Formal issues in Austronesian linguistics. Klumwer: Dordrecht.

[18] Kuno, S. and J. Robinson (1972). Multiple wh-questions. Linguistic Inquiry 3, 463-487.

[19] Kuno, S. (1978). Theoretical perspectives on Japanese linguistics. In John Hind and Irwin Howard (eds.), Problems in Japanese syntax and semantics. Japan: Kaitakusha.

[20] Ibn Yaqiil, Bahaa?-u-d-diin A. (1990). šarh Ibn Yaqiil. Cairo:Daar al-khair.

[21] Miyagawa, S. (1989). Structure and case marking in Japanese. Syntax and Semantics, 22. San Diego: Academic Press, INC.

[22] Saito, M. (1982). Case marking in Japanese: A preliminary study. Cambridge: MIT.

[23] Shibatani, M. (1977). Grammatical relations and surface cases. Language 53.4, 789-809.

[24] Ura, H. (2000). Checking theory and grammatical functions in universal grammar. Oxford: Oxford University Press.

[25] Wright, W. (1976). A Grammar of the Arabic language. London: Cambridge University Press.

Sabri S. Alshboul specializes in the cross-linguistic study of morphosyntactic representation of "Defaultness". He is also investigating the mechanism of "Grammaticalization" as represented in the morphosyntactic elements in Jordanian Arabic and Modern Standard Arabic. He was a member in the Graduate Studies English Proficiency Test, The Ministry of Higher Education and scientific research, Amman between 2009- 2010.

Maisoun I. Abu-Joudeh is an assistant professor in the Department of English Language and Literature at the Hashemite University. She has published in many international journals. Her current research interests include syntax, phonology, language teaching and translation. She is now teaching syntax in the Department of Language and Literature, the Hashemite University, Zarqa, Jordan.

Nazmi T. Al-Shalabi holds a Ph.D. in American Literature from Indiana University of Pennsylvania in the USA in 1993. Currently he is an associate professor of English literature at the Hashemite University in Jordan. He has so far published over thirty articles in international refereed journals, and his research interests focus on writing articles about American literature, English literature, Education, Translation, Cultural Studies, and Language. 